\title{
Análises preliminares de revistas da área de educação matemática
}

\author{
Preliminary analyses of academic journals in the \\ field of mathematical education
}

Marinez Meneghello Passos

Roberto Nardi

Sérgio de Mello Arruda

\begin{abstract}
Resumo
Este trabalho visa apresentar algumas considerações relacionadas a artigos publicados em periódicos de âmbito nacional da área de Educação Matemática. Os seguintes periódicos fizeram parte dessa análise: Boletim do GEPEM, Bolema, Educação Matemática em Revista, Zetetiké e Educação Matemática Pesquisa. Para a sistematização das informações foram destacadas as palavras-chave apresentadas pelos artigos e para os artigos que não as possuíam foi sugerida uma maneira de construí-las.

Palavras-chave: revistas; artigos; educação matemática

Abstract

This project intends to show some considerations about published papers in national journals of Mathematics Education. The journals that take part of the analysis were: Boletim do GEPEM, Bolema, Educação Matemática em Revista, Zetetiké, Educação Matemática Pesquisa. In order to systematize the information, it was used the papers' keywords. In the case of papers that did not have keywords, we suggested a way to create them.
\end{abstract}

Keywords: academic journals; papers; mathematical education.

\section{Introdução}

Como o título apresenta, neste trabalho temos o intento de observar com atenção, isto é, fazer uma análise preliminar em algumas revistas da área de Educação Matemática. 
Essa proposta foi sugerida como atividade de uma disciplina do programa de pósgraduação em Educação para a Ciência da Faculdade de Ciências da Universidade Estadual Paulista - Unesp, Campus de Bauru, intitulada - Introdução à pesquisa em educação em Ciências - e que tem como ementa a seguinte descrição:

A disciplina deverá discutir as origens e evolução da pesquisa em Educação em Ciências, o surgimento e consolidação de grupos de pesquisa no Brasil nas últimas décadas e as principais tendências da produção científica da área. (notas do professor da disciplina, entregue nas aulas iniciais do curso - março/2005)

Essa disciplina foi desenvolvida de forma múltipla, isto é, por meio de exposição oral dialogada, seminários, oficinas, discussões, trabalhos em grupo, elaboração de resenhas sobre publicações da área e a produção de levantamentos e sínteses sobre temas e publicações do interesse dos mestrandos e doutorandos que a cursavam.

Este trabalho refere-se a esta última indicação metodológica apresentada pelo docente responsável e que dentro da nossa proposta de pesquisa para o doutorado, nos vimos motivados a realizar uma análise preliminar de revistas em destaque na área de Educação Matemática no Brasil, com o objetivo de definir com maior clareza o nosso objeto de pesquisa na realização desta pós-graduação.

Entre os critérios para selecionar as revistas utilizamos as discussões com o professor da disciplina; algumas consultas via e-mail ou por telefone com alguns docentes da área de Educação Matemática do Departamento de Matemática da Universidade Estadual de Londrina entre eles as professoras Dra. Regina Luzia Corio de Buriasco e Dra. Márcia Cristina de C. Trindade Cirino, às quais deixamos aqui nossos agradecimentos. Diversas pesquisas pela Internet em site de busca e que na janela de descrição do que se pretendia selecionar incluímos 'revistas brasileiras da área de Educação Matemática', 'periódicos da área de Educação Matemática no Brasil', 'Educação Matemática revistas', entre outras.

Após esse período de discussão passamos a constituir o nosso acervo para a realização do levantamento relacionado ao contexto disciplinar. As revistas elencadas para serem pesquisadas foram: Boletim do GEPEM, Bolema, Educação Matemática em Revista, Zetetiké e Educação Matemática Pesquisa. Na seqüência apresentaremos alguns dados sobre o levantamento realizado e algumas considerações que pudemos observar. Devido ao volume do material sob análise e o caráter preliminar desta, o trabalho aqui descrito não pretende ser exaustivo, o que o espaço disponível nem permitiria, mas sim fornecer uma visão geral do que as revistas apresentam desde suas primeiras edições. Em momentos posteriores pretendemos nos aprofundar na análise dessas revistas e apresentar nossas considerações em outros eventos. 


\section{Metodologia}

\section{"Pegar para ver"}

Na coluna da Folha de São Paulo - Sinapse - da terça-feira 28 de julho de 2005, o colunista Rubem Alves, desenvolve sua argumentação em torno do tema 'Pegar para ver'; seu texto possui uma relação com relatos de fatos vividos e observados sobre a necessidade que as crianças possuem de tocar nos objetos e que se recusam a separar a visão do toque: como exemplificado, é impossível para eles entrar em uma loja de brinquedos com a mãozinha para trás (recomendação dos pais ou responsáveis).

No caso desse trabalho tivemos uma sensação deveras parecida - ver com as mãos todos os volumes das revistas em um mesmo momento foi emocionante. Chegamos a nos sentir como crianças diante de uma prateleira de brinquedos, sem saber qual deles pegar primeiro.

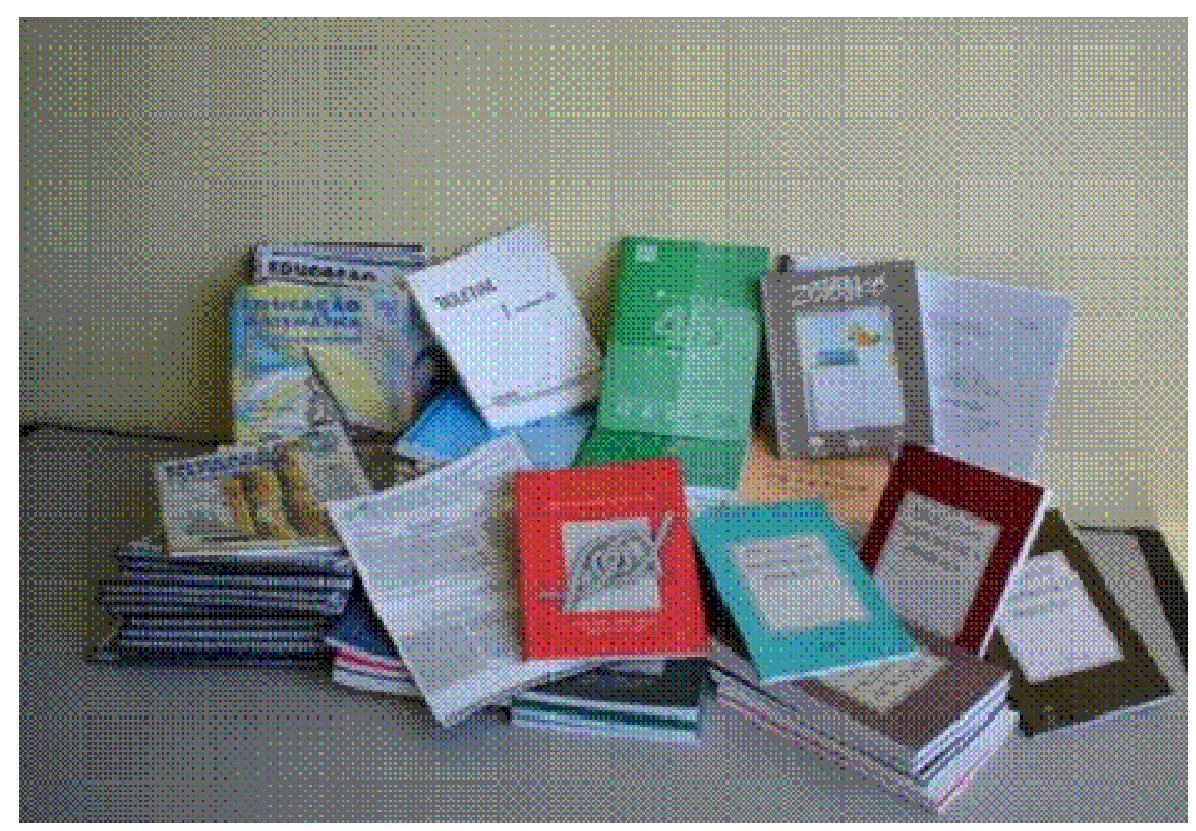

Figura 1: Coleções completas: Boletim GEPEM, Bolema, Educação

Matemática em Revista, Zetetiké, Educação Matemática Pesquisa

Nas várias oportunidades que tivemos contato com esses periódicos, isso ocorreu de forma fragmentada, ou seja, pesquisávamos em um ou outro exemplar, jamais havíamos 'tocado' ou 'pego' todos os volumes em uma mesma ocasião; nunca tínhamos observado o conjunto de revistas de uma mesma coleção ao mesmo tempo e muito menos as cinco coleções completas sobre um mesmo espaço físico (nossa mesa de estudo). 
Por outro lado - e, digamos, do lado adulto - podemos afirmar que estamos diante do que Popper (1975) nomina de "mundo 3":

Podemos dar ao mundo físico o nome de "mundo 1"; ao mundo de nossas experiências conscientes o de "mundo 2"; e ao mundo dos conteúdos lógicos de livros, bibliotecas, memórias de computador e similares o de "mundo 3". (assinalamentos do autor, p. 78)

Ao reportarmos essas considerações para o nosso fazer, vemos como produto do embate entre o mundo das "coisas" (mundo 1) e a mente (mundo 2), um universo de coisas construídas com elementos dos dois é constituído, dentre eles as obras de arte e as teorias da Ciência e da Matemática. Ou seja, é no amontoado de revistas, mostrado na fotografia anterior, que se materializa grande parte do conhecimento acumulado no Brasil, nas últimas décadas, do que se denomina de Educação Matemática. O contato com essa realidade fez do adulto, novamente criança, recuperando, talvez, o seu espírito investigativo, a vontade de descobrir esse universo.

\section{Revistas pesquisadas da área de Educação Matemática}

Na Figura 1 temos as revistas e números descritos na seqüência.

GEPEM - Boletim do grupo de estudos e pesquisas em Educação Matemática

Publicação do grupo de estudos e pesquisas em Educação Matemática - Gepem Instituto de educação da Universidade Federal Rural do Rio de Janeiro - RJ.

Boletim n.1, 1976; n.2, 1977; n.3, 1977; n.4, 1977; n.5, 1978; n.6, 1978; n.7, 1979; n.8, 1979; n.9 , 1980; n.10, 1980; n.11, 1981; n.12, 1981; n.13 , 1982; n.14, 1982; n.15, 1983; n.16 , 1984; n.17, 1985; n.18, 1986; n.19, 1986; n.20, 1987; n.21, 1987; n.22, 1988; n.23, 1988; n.24, 1989; n.25, 1989; n.26, 1990; n.27, 1990; n.28, 1991; n.29, 1991; n.30, 1992; n.31, 1993; n.32, 1994; n.33, 1995 - ISSN 0104-9739; n.34, 1998; n.35, 1999; n.36, 2000; n.37, 2000; n.38, 2001; n.39, 2001; n.40, 2002; n.41, 2003; n.42, 2003; n.43, 2003; n.44, 2004; Sumários correntes 1976/2000 - junho de 2004; n.45, 2004.

Bolema - Boletim de Educação Matemática - Boletim do grupo de estudos e pesquisas em Educação Matemática

Publicação da Unesp - Instituto de Geociência e Ciências Exatas - Departamento de Matemática - Programa de pós-graduação em Educação Matemática - Rio Claro - SP.

N.1, Inverno de 85; n.2, Primavera de 85; n.3, Primavera de 86; n.4, 1988; n.5, 1988; Especial 1, 1989; n.6, 1990; n.7, 1991; n.8, 1992 - ISSN 0103-636X; Especial. n.02, 1992; n.9, 1993; 
Especial 3, 1994; n.10, 1994; n.11, 1995; n.12, 1997; n.13, 1999; n.14, 2000; n.15, 2001; n.16, 2001; n.17, 2002; n.18, 2002; n.19, 2003; n.20, 2003; n.21, 2004; n.22, 2004; n.23, 2005.

\section{Educação Matemática em Revista}

Revista da Sociedade brasileira de Educação Matemática.

N.1, reedição, jul/2002 - ISSN 1517-3941 (publicada em 1993 - 1a edição); n.2, 1994; n.3, 1994; n.4, 1995; n.5, 1996; n.6, 1998 - ISSN 1517-3941; n.7, 1999; n.8, 2000; n.9/10, 2001; n.11, 2001; n.11A, ed. especial, 2002; n.12, 2002; n.13, 2003; n.14, 2003; n.15, 2003; n.16, 2004.

\section{Zetetiké}

Publicação do Círculo de estudo, memória e pesquisa em Educação Matemática da Faculdade de educação da Universidade de Campinas.

N.1, 1993 - ISSN 0104-4877; n.2, 1994; n.3, 1995; n.4, 1995; n.5, 1996; n.6, 1996; n.7, 1997; n.8, 1997; n.9, 1998; n.10, 1998; n.11, 1999; n.12, 1999; n.13/14, 2000; n.15/16, 2001; n.17/18, 2002; n.19, 2003; n.20, 2003; n.21, 2004; n.22, 2004.

\section{Educação Matemática Pesquisa}

Revista do Programa de estudos pós-graduados em Educação Matemática da Pontifícia Universidade Católica de São Paulo.

V.1, n.1, 1999 - ISSN 1516-5388; v.1, n.2, 1999; Especial pp.7-115, 2000; v.2, n.2, 2000; v.3, n.1, 2001; v.3, n.2, 2001; v.4, n.1, 2002; v.4, n.2, 2002; v.5, n.1, 2003; v.5, n.2, 2003; v.6, n.1, 2004.

\section{Resultado}

\section{As palavras-chave em foco}

Um dos dilemas encontrados na realização desse trabalho foi o de evidenciar uma forma de levantamento que nos mostrasse o que estava sendo considerado ou apresentado pelas revistas e que pudesse dar sentido à sistematização de informações relacionada à nossa coleta.

Durante essa busca tivemos contato com vários documentos. Na seqüência comentaremos sete deles.

O primeiro - Na tese de Nardi (2005) para a obtenção do título de livre-docente, o autor apresenta nas páginas 65 a 73 diversas informações sobre os EPEF - Encontro Nacional dos Professores de Física, entre elas temos: ano de ocorrência; local; número de participantes; 
quantidade de trabalhos apresentados; linhas, tendências ou enfoques presentes nesses trabalhos; formas de apresentação.

O segundo - As argumentações que Fiorentini (1993) apresenta, em um artigo de sua autoria no primeiro número da revista Zetetiké, nos motivou, ainda mais, na realização desse trabalho com as revistas e sentimos a necessidade de verificar o que elas poderiam, em um contexto macro, nesse primeiro momento, nos mostrar.

Para Fiorentini (1993):

Apenas uma pequena parcela (de educadores matemáticos $e$ pesquisadores) tem procurado verificar o que os colegas já investigaram a respeito de seu tema ou problema de pesquisa. Alguns justificam sua prática dizendo que os outros trabalhos não possuem o mesmo referencial teórico ou que não se inserem na mesma linha de pesquisa. Ora, não consultamos e citamos outros trabalhos apenas para Ihes dar continuidade ou para buscar apoio às nossas idéias. Fazemos isso também para questionar ou até refutar seus pressupostos ou suas conclusões e encaminhamentos. (p. 56)

Nesse trabalho o autor apresenta diversas informações sobre a pesquisa acadêmica em Educação Matemática, entre elas podemos destacar: ano em que as pesquisas foram produzidas/defendidas (pelo fato de se tratarem de dissertações e teses); distribuição das pesquisas segundo os títulos acadêmicos (mestrado, doutorado, livre-docência); distribuição das pesquisas segundo os estados brasileiros em que foram produzidas; as instituições; os orientadores; o nível de ensino pesquisado; uma síntese dos focos temáticos.

O terceiro - Em Garnica e Pereira (1997) os autores desenvolvem um trabalho que visa "apresentar algumas considerações sobre a área de Educação Matemática no estado de São Paulo" (p.59), para isso eles realizam a análise das comunicações científicas dos Anais dos Encontros Paulistas de Educação Matemática (EPEMs) ocorridos nos anos de 1989, 1991 e 1993, respectivamente nas cidades de Campinas, São Paulo e Bauru.

Em suas considerações sobre a metodologia adotada para a análise dos trabalhos científicos, os autores a intitulam 'quanti-qualitativa' descrevendo que:

O lado quantitativo refere-se aos dados numéricos dos quais lançamos mão para direcionar nossas conclusões - ainda que estas não sejam e nem mesmo a pretendemos definitivas. A quantidade, nesse caso, manteve-se como guia, nunca como determinante e em nenhum momento lançamos mão do rigor como classicamente conhecido pelas abordagens positivistas. [...] $O$ pesquisador coloca-se, pergunta, faz variações imaginativas, ordena e re- 
ordena seus dados com a intenção de compreendê-los, comprometendo-se com e por eles: é essa a face qualitativa da metodologia utilizada. (p.61)

No corpo do trabalho os autores destacam e quantificam a presença de conteúdos matemáticos, tais como álgebra, lógica, geometria, estatística, topologia e muitos outros; pinçam elementos denominados 'significativos' que podemos exemplificar relacionando algumas palavras apresentadas: psicologia, história, modelagem, construtivismo, enfoque social, criatividade, etnomatemática, pesquisa qualitativa (no quadro da página 65 os autores indicam 39 palavras e a quantidade de referências a elas). Sob o título de últimas convergências Garnica e Pereira se reportam ao quadro de Fiorentini (1993) e utilizam 13 focos temáticos elencados por ele e que relacionamos alguns na seqüência: currículo, prática docente, etnomatemática e educação de adultos, formação do professor de Matemática, fundamentos históricos-filosóficos e epistemológicos, ideologia e/ou concepções e significados.

O quarto - Em uma comunicação feita por Bicudo (1990) na revista Bolema de número 6, a autora destaca que naquela época já se podia verificar três linhas básicas de pesquisa no programa de mestrado em Educação Matemática do Instituto de Geociências e Ciências Exatas da Unesp - Campus de Rio Claro, as quais são: Tendências em Educação Matemática, Fundamentos filosóficos e científicos da Educação Matemática e Ensino e aprendizagem da Matemática.

O quinto - Com a leitura de Fiorentini e Sader (2000) tivemos contato com um estudo descritivo realizado pelos autores na busca de trabalhos surgidos no âmbito dos cursos de pósgraduação em Educação do Brasil e que sobre bases teórico-metodológicas consistentes investigassem o "quotidiano das aulas de Matemática, ou seja, estudos que procuram investigar/explorar a dinâmica ou as interações das aulas de Matemática". (p.1)

Dentre 72 trabalhos produzidos na década 1985-1995 os autores encontraram 19 que apresentavam esse enfoque e analisando-os em profundidade puderam retirar diversas informações, entre elas destacar focos de investigação que foram assim descritos pelos autores:

Análise do discurso ou da linguagem presentes no cotidiano da sala de aula, a formação/construção de conceitos ou a produção/negociação de significados em aulas de Matemática, as relações entre procedimentos didático-metodológicos e o desempenho/comportamento/aprendizagem dos alunos em aula, as relações e implicações entre concepções/crenças ou formação inicial do professor e a prática pedagógica em aula. (p.3 - tabela 2)

O sexto - Outra discussão que nos chamou a atenção e que foi também idealizada por Fiorentini (2002) é aquela em que o autor se propõem a mapear os trabalhos do GT-19 (grupo de trabalho de Educação Matemática da ANPEd) no período de 1998 a 2001 e avalia 48 trabalhos, descrevendo sobre suas origens e autorias e sistematizando as tendências temáticas (Tabela 2): 
Estudos sobre o professor de Matemática: caracterização, ideário, saberes; formação continuada; prática e desenvolvimento profissional e história.

Estudos cognitivos e metacognitivos: inclui estratégias, habilidades e processos cognitivos dos alunos.

\section{Estudos sobre o ensino de Matemática na Universidade.}

Estudos sobre as tendências teóricas, didático-pedagógicas e investigativas em Educação Matemática.

Estudos que utilizam a Engenharia Didática no ensino e aprendizagem de geometria (Produção, aplicação e análise de seqüências didáticas).

Estudos que tratam da Educação Matemática no contexto das políticas educacionais públicas.

Estudos sobre a produção de significados em atividades matemáticas.

Matemática em contexto não-escolar. (assinalamentos do autor, p.6)

O sétimo - Em Nardi (2003) o autor relaciona inúmeros dados sobre as II, III, IV, V Escolas de Verão para Professores de Prática de Ensino de Física, Química, Biologia e áreas afins. Formatado como capítulo de livro traz os objetivos dos eventos; quantifica os trabalhos desenvolvidos na forma de conferências, palestras, mesas-redondas, cursos, seminários de pesquisa, painéis, relatos de experiência, entre outros e classifica os trabalhos por tendências e enfoques, entre esses podemos destacar: prática do ensino de Física, Química, Biologia, Educação Matemática; dificuldades no planejamento do estágio supervisionado nas diversas áreas; experiências de implantação de laboratório para diversas disciplinas; estudos de caso sobre o registro de mudanças nas concepções de ensino e nas práticas docentes em sala de aula; construção de atividades de ensino a partir de concepções espontâneas; relato de experiência privilegiando a observação de didática e prática de ensino em várias disciplinas; lei de Diretrizes e Bases da Educação Nacional e temas relacionados a currículos, PCNs. (pp.50-51)

Os sete trabalhos destacados nessa composição contribuíram para o desenvolvimento da nossa proposta, no entanto cabe destacar que uma atenção especial foi dada às informações contidas no artigo de Fiorentini (1993). Ele foi a fonte que inspirou a seleção das palavras-chave. O quadro-síntese dos principais focos temáticos da pesquisa acadêmica brasileira em Educação Matemática (p.67) apresentado pelo autor mostrou-nos uma consonância entre os dados que estávamos levantando e as informações que o autor havia coletado e sistematizado naquela ocasião. 
A partir dessa decisão passamos a coletar as palavras-chave dos artigos que compunham as revistas, relacionar todas elas em um relatório, sendo que para cada revista geramos um relatório distinto. Em virtude do grande número de palavras-chave presentes nas revistas, nesse trabalho evidenciamos somente aquelas com mais de uma remissão.

Na seqüência apresentaremos o resultado dessa coleta. Contudo, para cada periódico tivemos que adequar nossa forma de trabalho pelo fato de que suas características editoriais nem sempre foram padronizadas e de periódico para periódico há algumas diferenças na estrutura e na composição dos elementos necessários para a publicação dos artigos.

No entanto, apresentamos ao leitor no parágrafo que antecede a relação de palavras-chave algumas considerações feitas durante essa tomada de dados. Antecipadamente comentamos que os periódicos mais recentes apresentam em todos os seus artigos as palavraschave. Destacamos também que a ordem em que relacionamos a seguir as revistas está vinculada à ordem em que recebemos os periódicos, mediante as negociações realizadas com os responsáveis por elas.

\section{Educação Matemática Pesquisa}

Cabe lembrar que para essa coleta foram observadas as palavras-chave inclusas no periódico - todos os artigos possuem esse destaque.

Observe as palavras com mais de uma remissão e em ordem decrescente de quantificação.

Tabela 1: palavras-chave, 'Educação Matemática Pesquisa'.

\begin{tabular}{|l|l|}
\hline Currículos. 6 & Discurso do professor. 2 \\
História da matemática. 6 & Ensino. 2 \\
Educação matemática. 5 & Internet. 2 \\
Epistemologia. 4 & Matemática escolar. 2 \\
Formação de professores. 4 & Prova. 2 \\
Computador na educação matemática. 3 & Representações. 2 \\
Didática. 3 & Software. 2 \\
Geometria. 3 & Visualização geométrica. 2
\end{tabular}




\section{Zetetiké}

Nossa coleta pautou-se na observação das palavras-chave destacadas pelo periódico (mais de $95 \%$ dos artigos as possuíam) e para os artigos que não as tinham (menos de $5 \%$ ) consideramos verbetes do título do artigo, tendo como critério para seleção desses verbetes a relação de palavras-chave apresentada pelo próprio periódico. Veja um exemplo de como fizemos essa construção. Ao nos depararmos com o artigo de título "Ensino da matemática: reflexões para a aprendizagem significativa" presente na revista número 2 de 1994, destacamos como palavraschave - ensino de matemática e aprendizagem significativa, cabe lembrar que esse artigo não possuía um resumo. Caso ele o tivesse nós consideraríamos o texto do resumo como elemento a ser analisado para a construção da relação de palavras-chave do artigo.

Na seqüência apresentamos as palavras com mais de uma remissão e em ordem decrescente de quantificação.

Tabela 2: palavras-chave, 'Zetetiké'.

Formação de professores. 20

Educação matemática. 19

Ensino. 11

Avaliação. 9

Computadores. 8

Currículo. 8

Concepções. 7

Didática. 7

Licenciatura. 7

Educação. 3

Funções. 3

História. 3

Interdisciplinaridade. 3

Matemática. 3

Reforma. 3

Resolução de problemas. 3

Álgebra. 2
Aprendizagem. 6

Cálculo. 6

Modelagem. 5

Epistemologia. 4

Etnomatemática. 4

Geometria. 4

Metodologia. 4

Projetos. 4

Representação. 4

Filosofia. 2

Grupos (formação/constituição). 2

História da educação. 2

História da matemática. 2

História do ensino da matemática. 2

Meta-cognição. 2

Percepção. 2

Pré-escola. 2 
Algoritmo. 2

Atitudes. 2

Construção de conceitos. 2

Crenças. 2

Educação de jovens e adultos. 2

Ensino médio. 2

Ensino superior. 2

Euclides Roxo. 2

Experimentação. 2
Profissionalização. 2

Psicanálise. 2

Psicologia. 2

Reflexão. 2

Significado. 2

Tendências. 2

Teoria e prática. 2

Valor posicional. 2

Visualização. 2

\section{GEPEM}

Para essa coleta foram observadas as palavras-chave destacadas pelo periódico e que estão apresentadas em $13 \%$ dos artigos. Gostaríamos de destacar que os artigos que trazem palavras-chave estão nas revistas dos anos de 2004, 2003 e 2002 e são as de números 45, 44, 43, 42, 41 e 40. Para os artigos que não possuíam palavras-chave - cerca de $87 \%$ deles, consideramos verbetes do título do artigo (84\%) e aqueles que possuíam um resumo introdutório (3\%) esse foi considerado para a seleção das palavras. Destacamos novamente que o critério para a seleção dos verbetes dos títulos e dos resumos considerou a relação de palavras-chave apresentadas pelo próprio periódico em seus seis últimos números publicados.

Para que o leitor compreenda como construímos a relação de palavras-chave para os artigos que não as possuíam, mostraremos alguns exemplos relacionados a este periódico.

Nesse parágrafo apresentaremos as palavras-chave presentes nos volumes 45,44 e 43: desafios lógicos, conceito de função, formação de professores de matemática, práticas pedagógicas, geometria não-euclidiana, representações semióticas, ensino médio, educação matemática, tecnologias, proposta didática pedagógica, representação gráfica de funções, calculadoras, multiplicação, investigação em aula, atividades introdutórias, geometrias nãoeuclidianas, geometria do táxi, materiais concretos, estratégia argumentativa, montagem, discurso, argumento, educação matemática, aprendizagem dialógica, experiência prévia, geração de sentido, altas expectativas, transformação, linguagem, metonímias, exemplos, múltiplo, divisor, conhecimento, significado, proporção, séries iniciais, crianças, alternativas pedagógicas, cálculo mental, quantificadores básicos, índice de dificuldade, níveis, crenças, aprendizagem, software, implementação, informes, valorização, objetivo, motivação, dimensão afetiva, 
demonstração, geometria, formação inicial de professores, pesquisa, formação de professores, números.

Com essas palavras em mãos vamos construir agora uma simulação do realizado, quando nos deparávamos com um título de artigo como este "Tecnologia e avaliação: um olhar através dos parâmetros curriculares nacionais do ensino médio" - n.37, agosto de 2000 - destacamos as seguintes palavras: tecnologia, avaliação, $\mathrm{PCN}^{\prime}$, ensino médio (nesse caso o artigo não apresentava um resumo).

Vejamos a seguir um exemplo em que o artigo apresenta resumo. Título do artigo: "Desenvolvimento profissional baseado na web: perspectivas para a educação geométrica" n.39, setembro de 2001 - destacamos as seguintes palavras: formação docente, formação continuada, tecnologia, ensino-aprendizagem, geometria, computadores, meios educacionais.

Na seqüência incluímos as palavras com mais de uma remissão em ordem decrescente de quantificação.

Tabela 3: palavras-chave, 'GEPEM'.

\begin{tabular}{|l|l|}
\hline Educação matemática. 26 & Professores de matemática. 3 \\
Ensino da matemática. 24 & Relato de experiência. 3 \\
Resolução de problema. 10 & Relato. 3 \\
Geometria. 10 & Sétima série. 3 \\
Pesquisa. 9 & Alfabetização algébrica. 2 \\
Argumentação. 6 & Álgebra linear. 2 \\
Ensino de geometria. 6 & Análise crítica. 2 \\
Ensino médio. 6 & Cálculo mental. 2 \\
Ensino. 6 & Equação e função. 2 \\
Linguagem. 6 & Estatuto matemático. 2 \\
Matemática. 6 & Estudo de caso. 2 \\
Segundo grau. 6 & Experiência. 2 \\
Aprendizagem. 5 & Fermat. 2 \\
Dificuldade. 5 & Formação inicial de professores. 2 \\
Formação de professores de matemática. 5 & Geometria não-euclidiana. 2 \\
Primeiro grau. 5 & Grupos cíclicos. 2 \\
\hline
\end{tabular}




\begin{tabular}{|c|c|}
\hline Atividade algébrica. 4 & Incógnita e variável. 2 \\
\hline Avaliação. 4 & Investigação. 2 \\
\hline Computador. 4. & Livro didático. 2. \\
\hline Educação. 4 & Logo - linguagem de programação. 2 \\
\hline Formação de professores. 4 & Máximo divisor comum. 2 \\
\hline Módulo instrucional. 4. & Metáfora. 2 \\
\hline Software. 4 & Métodos. 2 \\
\hline Tecnologia. 4 & Modelagem. 2 \\
\hline Álgebra. 3 & Nível universitário. 2 \\
\hline Calculadora. 3 & Noção de status. 2 \\
\hline Concepções. 3 & Novas tendências. 2 \\
\hline Conhecimento profissional. 3 & Número. 2 \\
\hline Construção de conceito. 3 & Números naturais. 2 \\
\hline Didática da matemática. 3 & Números negativos. 2 \\
\hline Ensino fundamental. 3 & Objetivos. 2 \\
\hline Equação. 3 & Olimpíadas. 2 \\
\hline Função. 3 & Pensamento e linguagem. 2 \\
\hline Informática. 3 & Raiz quadrada. 2 \\
\hline Matemática moderna. 3 & Reflexões. 2 \\
\hline Mello e Souza. 3 & Revisão bibliográfica. 2 \\
\hline Notícias. 3 & Rupturas. 2 \\
\hline Pós-graduação. 3 & Sala de aula. 2 \\
\hline Prática de ensino. 3 & Salto para o futuro. 2 \\
\hline Pré-escolar. 3 & Séries iniciais. 2 \\
\hline Professor. 3 & Significados. 2 \\
\hline Terceir & \\
\hline
\end{tabular}




\section{Bolema}

As palavras-chave destacadas pelo periódico e que estão apresentadas em $11 \%$ dos artigos orientaram nossa seleção. Informamos que os artigos que trazem palavras-chave estão nas revistas dos anos de 2004 e 2005 e são as de números 21, 22 e 23 . Para os artigos que não possuíam palavras-chave - cerca de $89 \%$ deles, consideramos verbetes do título do artigo (43\%) e aqueles que possuíam um resumo introdutório (46\%) esse foi considerado para a seleção das palavras.

Cabe lembrar ao leitor que a relação de palavras construídas por nós segue modelo similar aos exemplos apresentados no caso da revista do GEPEM.

A seguir incluímos as palavras com mais de uma remissão e em ordem decrescente de quantificação.

Tabela 4: palavras-chave, 'Bolema'.

\begin{tabular}{|l|l|}
\hline Educação matemática. 21 & Conhecimento matemático. 2 \\
Etnomatemática. 7 & Conhecimento. 2 \\
Ensino de matemática. 5 & Demonstração matemática. 2 \\
Modelagem. 5 & Desenvolvimento profissional. 2 \\
Fenomenologia. 4 & Epistemologia. 2 \\
História da matemática. 4 & Escola pública. 2 \\
Significados. 4 & Ética. 2 \\
Aprendizagem. 3 & Filosofia da educação matemática. 2 \\
Assimilação solidária. 3 & Filosofia. 2 \\
Computadores. 3 & Formação social. 2 \\
Currículo. 3 & História. 2 \\
Demonstração. 3 & Livro didático. 2 \\
Ensino fundamental. 3 & Modelagem matemática. 2 \\
Ensino. 3 & Não congruência de triângulos. 2 \\
Ensino-aprendizagem. 3 & Pesquisa qualitativa. 2 \\
Geometria. 3 & Representações. 2 \\
\hline
\end{tabular}




\begin{tabular}{|l|l|}
\hline Matemática. 3 & Saber escolar. 2 \\
Saber matemático. 3 & Situações-problema. 2 \\
Congruência de triângulos. 2 & Sociologia. 2 \\
Conhecimento geométrico. 2 & Transposição didática. 2 \\
\hline
\end{tabular}

\section{Educação Matemática em revista}

Neste caso foram observadas as palavras-chave destacadas pelo periódico e que estão apresentadas em $32 \%$ dos artigos. Para os artigos que não possuíam palavras-chave - cerca de $68 \%$ deles, consideramos verbetes do título do artigo (50\%) e aqueles que possuíam um resumo introdutório (18\%) esse foi considerado para a seleção das palavras.

Realizamos a construção da lista de palavras-chave dos artigos que não as possuíam seguindo os mesmos critérios exemplificados durante a tomada de informação junto ao boletim do GEPEM.

Veja a seguir a relação de palavras com mais de uma remissão e em ordem decrescente de quantificação.

Tabela 5: palavras-chave, 'Educação Matemática em revista'.

\begin{tabular}{l|l} 
Geometria. 12 & Jogos. 3 \\
Educação matemática. 11 & $\begin{array}{l}\text { Linguagem matemática. } 3 \\
\text { Modelagem. } 3\end{array}$ \\
Formação de professores. 11 & $\begin{array}{l}\text { Alfabetização matemática. } 2 \\
\text { Calculadora. } 2\end{array}$ \\
Ensino de geometria. 8 & Campos conceituais. 2 \\
Avaliação. 6 & Cidadania. 2 \\
Ensino fundamental. 5 & Competências. 2 \\
Função. 5 & Concepções. 2 \\
Licenciatura. 5 & Contrato didático. 2 \\
Professor de matemática. 5 & Criatividade. 2 \\
Aprendizagem. 4 & Desenvolvimento profissional. 2 \\
Computador. 4 & Ensino médio. 2
\end{tabular}




\begin{tabular}{|l|l|}
\hline Ensino-aprendizagem. 4 & Epistemologia. 2 \\
Metodologia. 4 & Equação. 2 \\
PCN's. 4 & História da matemática. 2 \\
Resolução de problemas. 4 & História. 2 \\
Software. 4 & Informática. 2 \\
Cabri. 3 & Internet. 2 \\
Conhecimento matemático. 3 & Investigação. 2 \\
Conhecimento prévio. 3 & Números. 2 \\
Etnomatemática. 3 & Professor reflexivo. 2 \\
Formação inicial. 3 & Sala de aula. 2 \\
Gráficos. 3 & Significados. 2 \\
\hline
\end{tabular}

\section{Análises e considerações sobre a continuidade de pesquisa}

Muitos podem dizer que o que foi levantado por essa busca nos documentos, já se sabia era um resultado esperado -, no entanto preferimos deixar o 'achismo' de lado e caminhar em direção à comprovação do que era considerado 'fato' e dar a ele um caráter de direito. Com certeza estaríamos nos colocando em uma posição mais confortável para afirmar que as suspeitas foram realmente comprovadas.

Ao observarmos a lista de palavras-chave e a freqüência com que elas se apresentam nas revistas, vemos que essas palavras contribuíram para identificar artigos que possuem elementos que tenham entre si algum parentesco ou que pertençam a uma mesma área de interesse, neste caso para fins de pesquisa.

Se assumirmos que as palavras-chave encerram em si o significado global de um contexto e nos detivermos nas duas palavras com o maior índice de freqüência nas cinco revistas: GEPEM Educação Matemática (26) e Ensino de Matemática (24); Bolema - Educação Matemática (21) e Etnomatemática (7); Educação Matemática em Revista - Geometria (12), Educação Matemática e Formação de professores (11); Zetetiké -Formação de professores (20) e Educação Matemática (19); Educação Matemática Pesquisa - Currículos (6) e História da Matemática (6), poderíamos concluir que esses foram os temas ou assuntos centrais nos últimos 30 anos (primeiro boletim do GEPEM é datado de 1976) na área de Educação Matemática no Brasil. No entanto, acreditamos 
que essa consideração é o ponto de partida para uma reflexão em andamento e, que, para afirmarmos que essas palavras-chave realmente apontam para os temas ou assuntos discutidos com certa freqüência no contexto acadêmico e de pesquisa na área de Educação Matemática, teremos que realizar na continuidade, um segundo nível de análise, buscando realizar outras categorizações.

Como comentado em outro momento desse texto, compusemos nesse trabalho um levantamento quantitativo, contudo pretendemos dentro em breve galgar pelas trilhas qualitativas, focando com uma diversidade de olhares cada um dos temas representados pelas palavras-chave com maior índice de freqüência.

Outro fato que nos chama a atenção nessa ocasião e que pudemos observar ao realizamos um paralelo entre os quadros com as informações e as sistematizações feitas por Garnica e Pereira (1997), é a existência de certa consonância entre os verbetes que os compõem e as palavras-chave presentes no levantamento realizado nas cinco revistas.

Em relação ao que foi destacado por Bicudo (1990) pudemos comprovar que palavraschave relacionadas a essas linhas são muitos freqüentes nos artigos presentes nos periódicos.

Ao retomarmos o trabalho de Fiorentini e Sader (2000), e, em especial, o destaque dado aos focos de investigação, podemos detectar a presença das palavras-chave que encontramos na nossa coleta de dados juntos aos periódicos da área de Educação Matemática no Brasil.

Novamente temos a convergência entre as palavras que compõem os focos temáticos e as palavras-chave que detectamos na nossa coleta, bem como uma certa coerência entre as freqüências, isto é, aquelas que aparecem com maior freqüência também compõem as frases que intitulam os focos temáticos.

Mediante reflexões sobre o percurso realizado durante essa busca nos deparamos com algumas questões. Para várias conseguimos dar um encaminhamento, entretanto para outras vemos que é necessário um fôlego a mais sobre o material em análise a fim de que possamos afeiçoar outras considerações.

A seguir elencamos de forma epitomada uma relação dessas perguntas: Em suma, o que as palavras-chave procuram nos mostrar? Seria uma forma de localizamos rapidamente o assunto central do artigo? Nesse primeiro contato que tivemos com esses periódicos, nos parece que esta seja uma consideração razoável, tanto que para os artigos que coletamos as palavras-chave via resumo ou título, procuramos observá-los com certa profundidade, verificando essa coerência.

Estaria a construção de palavras-chave que realizamos coerente com metodologias de pesquisa? Por meio das palavras-chave que outras observações poderíamos realizar? A que elas nos levariam? Em um segundo momento que olhares poderíamos lançar sobre esses periódicos? 
Para finalizar nossas discussões buscamos acontecimentos que permearam diversos momentos da nossa vida acadêmica - o contato com as revistas nos remetia constantemente a um passado, às vezes próximo e em alguns casos distante - tivemos a oportunidade de presenciar reflexões encadeadas pelo professor Nilson José Machado, da Faculdade de Educação da USP, nelas ele apresenta uma idéia básica que adotamos para justificar o nosso fazer com relação a essa coleta, em resumo ele diz, 'o que importa é que a escola consiga transformar conteúdo em conhecimento aplicável à vida do aluno'.

Mediante essa consideração pudemos sentir que, a análise preliminar realizada nas revistas está relacionada em grande parte com a fala do professor Nilson Machado, a escola (nesse caso a Faculdade de Ciências, por meio do curso de pós-graduação e da disciplina por nós cursada) proporcionou um espaço para que transformássemos os conteúdos dos periódicos em conhecimento aplicável à composição de nossa pesquisa, ou seja, na composição desse levantamento e de trabalhos relacionados a ele tivemos uma idéia geral de como os temas/assuntos evoluíram/se apresentaram na área de Educação Matemática no Brasil.

De um modo geral, o trabalho de organizar as informações nesse conjunto constituído pelas principais revistas da área de Educação Matemática, se assemelha a adentrar uma floresta. São muitas as espécies existentes e é preciso, de início, encontrar uma maneira de classificá-las. Pelo nosso entender, as palavras-chave teriam esse propósito, tendo sido a taxonomia desse universo o objetivo principal do presente trabalho. Quiçá, a sua continuidade preveja a escolha de uma ou duas das espécies para um estudo mais detalhado.

\section{Referências}

BICUDO, Maria Aparecida Viggiani. Algumas pesquisas em Educação Matemática realizadas no programa de mestrado em Educação Matemática do Instituto de Geociências e Ciências Exatas da Unesp - Campus de Rio Claro.In: Bolema- Boletim de Educação Matemática, ano 3, n.6, pp.45-47, 1990.

FIORENTINI, Dario. Memória e análise da pesquisa acadêmica em Educação Matemática no Brasil: o banco de teses do CEMPEM/FE - Unicamp. In: Zetetiké, ano 1, n.1, pp.55-76, mar/1993.

FIORENTINI, Dario; SADER, Patrícia Maria Almeida. Tendências da pesquisa brasileira sobre a prática pedagógica em Matemática: um estudo descritivo. In: 22a REUNIÃO ANUAL - Associação Nacional de Pós-Graduação e Pesquisa em Educação - ANPEd. Caxambu, 24 a 28 de setembro de 2000. Disponível em : <http://www.gt19edu/mat.br/reunioesanteriores22.htm>. Acesso em: 30 jun. 2005. 
FIORENTINI, Dario. Mapeamento de balanço dos trabalhos do GT-19 (Educação matemática) no período de 1998 a 2001. In: 25a REUNIÃO ANUAL - Associação Nacional de Pós-Graduação e Pesquisa em Educação - ANPEd. Caxambu, 29 de setembro a 2 de outubro de 2002. Disponível em: <http://www.anped.org.br/25/te25.htm>. Acesso em: 30 jun. 2005.

GARNICA, Antonio Vicente Marafioti; PEREIRA, Maria Eliza Furquim. A pesquisa em Educação Matemática no Estado de São Paulo: um possível perfil. In: Bolema - Boletim de Educação Matemática, ano 11, n.12, pp.59-74, 1997.

NARDI, Roberto. A Educação em Ciências, a Pesquisa em Ensino de Ciências e a Formação de Professores no Brasil. In: TED - Tecnología, Episteme y Didaxis. Bogotá, Colombia, v. Extra, p.19$33,2003$.

NARDI, Roberto. A área de ensino de Ciências no Brasil: fatores que determinaram sua constituição e suas características segundo pesquisadores brasileiros. Março/2005, 166p. Tese (Livre-docência) - Universidade Paulista. Faculdade de Ciências, Bauru.

POPPER, Kari Raimund. Conhecimento objetivo: uma abordagem evolucionária. Belo Horizonte: Editora Itatiaia; São Paulo: Editora da Universidade de São Paulo, 1975, 394p.

Marinez Meneghello Passos - UEL - Universidade Estadual de Londrina - Departamento de Matemática

marinezmp@sercomtel.com.br

Roberto Nardi - UNESP - Universidade Estadual Paulista - Departamento de Educação r.nardi@uol.com.br

Sérgio de Mello Arruda - UEL - Universidade Estadual de Londrina - Departamento de Matemática renop@uel.br 